\begin{tabular}{|l|c|c|c|c|}
\hline $\begin{array}{l}\text { Cuadernos de Investigación Geográfica } \\
\text { Geographical Research Letters }\end{array}$ & 2019 & N $^{\circ} 45(1)$ & pp. 367-392 & eISSN 1697-9540 \\
\hline
\end{tabular}

\title{
GEOMORFOLOGÍA PARAGLACIAL ASOCIADA A LA INESTABILIDAD DE LADERAS EN EL BRAZO NORTE DEL LAGO ARGENTINO, PATAGONIA, ARGENTINA
}

\author{
S. MORAGUES ${ }^{1 *}$, M.G. LENZANO ${ }^{1}$, S. MOREIRAS ${ }^{1,2}$, L. LENZANO ${ }^{1,3}$ \\ ${ }^{1}$ Instituto Argentino de Nivología, Glaciología y Ciencias Ambientales (IANIGLA)-Centro Científico \\ Tecnológico (CCT), CONICET, 5500 Mendoza, Argentina. \\ ${ }^{2}$ Departamento de Agrícola Aplicada, Facultad de Ciencias Agrarias, Universidad Nacional de Cuyo, \\ Almirante Brown 500, M5528AHB Chacras de Coria-Luján de Cuyo, Mendoza, Argentina. \\ ${ }^{3}$ Facultad de Filosofía y Letras, Universidad Nacional de Cuyo, Centro Universitario, Parque San \\ Martín s/n, M5502JMA Mendoza, Argentina.
}

RESUMEN. El retroceso y adelgazamiento de los glaciares a nivel mundial en las últimas décadas inciden directamente sobre la estabilidad de las laderas. La cuenca del glaciar Upsala y los glaciares del Brazo Norte del lago Argentino, han sufrido un marcado retroceso generando valles con pronunciadas pendientes y cubiertas con depósitos morrénicos inestables. Las laderas se encuentran fuertemente desestabilizadas, favoreciendo la generación de procesos geomorfológicos paraglaciales. El objetivo de este estudio es identificar y analizar la geomorfología paraglacial, asociada a los procesos de inestabilidad. Se realiza un análisis geomorfológico del terreno a través de la combinación de parámetros morfométricos y factores intervinientes que condicionan y desencadenan estos procesos, mediante el uso de imágenes de satélite. Los resultados muestran que la geomorfología paraglacial se encuentra influenciada por la combinación de: (i) parámetros morfométricos del terreno, entre ellos, elevaciones del terreno superiores a $700 \mathrm{~m}$, pendientes promedios con un rango entre $25^{\circ}-45^{\circ}$, orientación de las laderas este-noroeste con mayor insolación, curvatura cóncava del terreno y rugosidad leve a moderada (0,40-0,65); (ii) factores condicionantes, material morrénico depositado por los glaciares, afloramientos rocosos meteorizados y cobertura vegetal; (iii) factores desencadenantes, aporte de agua subterránea por infiltración de lagunas proglaciales y aporte superficial por precipitaciones, deshielo y escurrimiento, variación de temperaturas del aire y del suelo y variación del nivel del lago. En síntesis, las laderas que presentan mayores procesos geomorfológicos paraglaciales, producto de procesos de remoción en masa, son las que se encuentran en contacto directo con los glaciares Upsala, Bertacchi y Cono, la ladera occidental del canal Upsala y algunas zonas de los valles Moyano y Norte. El área se caracteriza por una combinación de ambientes glacial y paraglacial, siendo cada uno parte integral de la evolución del entorno. 
Paraglacial geomorphology associated with slope instability in the North Branch of the Argentino Lake, Argentinean Patagonia

ABSTRACT. The worldwide retreat and thinning of glaciers in recent decades have a direct impact on the stability of the slopes. The Upsala glacier basin and the glaciers of the North Branch of Argentino Lake have suffered a marked retreat, generating valleys with steep slopes and covered with unstable moraine deposits. Therefore, the slopes are strongly destabilized, favoring the generation of paraglacial geomorphological processes. The main goal of this study is to identify and analyze the paraglacial geomorphology associated with instability processes. We analysis the area through the combination of morphometric parameters and intervening factors that condition and trigger these processes by satellite images. The results show that paraglacial geomorphology is influenced by the combination of: (i) terrain morphometric parameters as, among others, terrain elevations exceeding $700 \mathrm{~m}$ ASL, average slopes with a range between $25^{\circ}-45^{\circ}$, east-northwest slopes aspects with greater insolation, concave curvature of the terrain and slight to moderate roughness (0.40-0.65); (ii) conditioning factors, moraine material deposited by glaciers, weathered rock outcrops and vegetation cover; (iii) triggering factors, groundwater infiltration by proglacial lagoons and surface infiltration by rainfall, thaw and runoff, variation of air and soil temperatures and variation of lake level. In conclusion, the slopes with the greatest paraglacial geomorphological processes resulting from mass removal processes are those in direct contact with the Upsala, Bertacchi and Cono glaciers, the western slope of the Upsala channel and some areas of the Moyano and Norte valleys. The area is characterized by a combination of glacial and paraglacial environments, each being an integral part of the evolution of the environment.

Palabras clave: Geomorfología paraglacial, inestabilidad de laderas, parámetros geomorfométricos, factores condicionantes y desencadenantes.

Key words: Paraglacial geomorphology, slope instability, geomorphometric parameters, conditioning and triggering factors.

Recibido: 23 de octubre de 2018 Aceptado: 30 de diciembre de 2018

*Correspondencia: Silvana Moragues, Instituto Argentino de Nivología, Glaciología y Ciencias Ambientales (IANIGLA)-Centro Científico Tecnológico (CCT), CONICET, Avda. Ruiz Leal s/n, Parque General San Martín, CP 5500, Mendoza, Argentina. E-mail: smoragues@mendoza-conicet.gob.ar

\section{Introducción}

En ambientes fríos, el retroceso del hielo de los glaciares expone paisajes que se encuentran en un estado inestable. Por lo tanto, es susceptible a que se produzcan modificaciones tales como erosión y liberación de sedimentos que exceden en gran medida 
las tasas de exposición del fondo de la ladera (Ballantyne, 2002). Esta actividad geomorfológica acelerada se denomina paraglacial, término definido por Ryder (1971a, b). Los procesos paraglaciales son el principal factor evolutivo para pendientes con sedimentos después de la deglaciación (Mercier et al., 2009). La retracción generalizada de los glaciares a escala mundial durante los siglos XX y XXI, ha desencadenado numerosos procesos geomorfológicos paraglaciales, es decir, procesos sobre la superficie terrestre, aporte de sedimentos, accidentes geográficos y paisajes condicionados por la glaciación y la deglaciación (Ballantyne, 2002; Slaymaker, 2009). En estos ambientes anteriormente cubiertos por hielo, la transición entre las condiciones glaciales y periglaciales, resulta en un reajuste paraglacial acelerado, con procesos geomórfológicos muy activos (Serrano et al., 2018). Estos procesos modifican las tensiones de las laderas e influyen en su estabilidad y, por ende, los cambios en la estabilidad de la pendiente durante la deglaciación pueden ser considerados en el marco de la geomorfología paraglacial (McColl, 2012).

La contribución de la geomorfología al comportamiento de las laderas en áreas frías es ciertamente significativa (Aristizábal y Yokota, 2006). Las zonas montañosas que son afectadas por la deglaciación suelen presentar gran variedad de procesos paraglaciales que implica una progresiva denudación de las huellas dejadas por los cuerpos de hielo (Santos-González et al., 2018). Fitzsimons (1996), señala que la redistribución de los restos glaciogénicos es más rápida en el último terreno deglaciado, debido a la disponibilidad de agua proveniente de la fusión glaciar. Una vez que la deglaciación de un área está completa, la transferencia de sedimentos se ralentiza radicalmente.

La influencia de los atributos del terreno, como la topografía, litología, procesos de modelado glaciar y formas del relieve, son esenciales en el desarrollo y entendimiento de la dinámica paraglacial y sus geoformas asociadas, entre ellas, la ocurrencia de deslizamientos (Aristizábal y Yokota, 2006; Santos-González et al., 2018). Las formas de relieve, los paisajes y las pendientes no son estáticos e invariables, sino que son dinámicos y se desarrollan a través del tiempo (Tooth y Viles, 2014). Por esta razón, la identificación de la geomorfología de las laderas, que permite estudiar a las geoformas como elemento de investigación, es abordada desde la cuantificación de los procesos que intervienen junto con los factores que condicionan y desencadenan la inestabilidad.

Según Zinck (2012), el componente externo de una geoforma es su figura o forma, que indica una combinación de atributos morfográficos y morfométricos. La morfometría solo contribuye a la caracterización automatizada de los atributos dimensionales de las geoformas (rasgos externos). Tal es el caso de los valles glaciares que son definidos como formas espectaculares debido a la erosión de las masas de hielo. Un ejemplo es el Campo de Hielo Patagónico Sur (CHPS), con la evidente retracción de sus glaciares, particularmente la del glaciar Upsala (Aniya et al., 1997; Sakakibara y Sugiyama, 2014; Moragues et al., 2018, entre otros). La cuenca del Upsala presenta una combinación de procesos glaciales y paraglaciales, constituyendo un ambiente complejo. Se han realizado investigaciones de la geomorfología glaciar del CHPS (Caldenius, 1932; Malagnino y Strelin 1992; Glasser et al., 2005, 2008; Aniya et al., 2007; Glasser y Ghiglione, 2009; Strelin et al., 2014), pero existe 
una carencia de estudios en la cuenca del Upsala, de la geomorfología paraglacial, asociada a la inestabilidad de las laderas.

El presente estudio se centra en la inestabilidad de las laderas, mostrando diversas geoformas, producto de procesos y agentes geomórfológicos. Por ello, el objetivo es identificar y analizar la geomorfología paraglacial asociada a los procesos de inestabilidad del área del Brazo Norte del lago Argentino. Se realiza un análisis del terreno a través de la combinación de parámetros morfométricos, con factores condicionantes y desencadenantes de dichos procesos. De esta manera, el estudio contribuye al entendimiento e interpretación del paisaje actual y la evolución, a largo plazo, de los procesos de reajustes paraglaciares de las laderas.

\section{2. Área de estudio}

El área se encuentra ubicada en el CHPS, extensa masa de hielo terrestre compuesta por 48 glaciares de salida con una altitud media de $1.355 \mathrm{~m}$ (Aniya et al., 1996). Con $12.550 \mathrm{~km}^{2}$ de superficie (Skvarca et al., 2010), el CHPS es la mayor extensión de hielo en el hemisferio sur, a excepción de la Antártida (Aniya y Skvarca, 1992), cubriendo grandes extensiones de la región montañosa. Estas masas de hielo comenzaron a sufrir una disminución en su superficie, producto de la intervención de varios factores, dejando como consecuencia un paisaje modelado por la acción glaciar y pendientes cubiertas por depósitos glaciogénicos. En la cuenca del lago Argentino los glaciares comenzaron a retroceder en el Holoceno temprano (Strelin et al., 2014). El canal Upsala es uno de estos valles modelados por el hielo, con una profundidad de $\sim 600 \mathrm{~m}$ en el frente del glaciar Upsala (Naruse y Skvarca, 2000; Sugiyama et al., 2016) y sus alrededores como los valles del río Moyano, río Norte, península Herminita, bahía Onelli y canal Spegazzini (Fig. 1). Hacia el oeste del canal aparecen las primeras estribaciones de la zona Andina, cubiertas con depósitos de los sistemas morrénicos Pearson I y II (Strelin et al., 2014).

La zona de estudio está compuesta por rocas metamórficas de bajo grado (Fm. Pizarras) que constituyen el basamento de la región (Steffen, 1910). Estas rocas están cubiertas por la secuencia volcano-sedimentaria jurásica del Complejo El Quemado (CEQ), ignimbritas, riolíticas, tobas y flujos de lava (Kraemer y Riccardi, 1997). Estas litologías afloran en la margen oriental del glaciar Upsala. La morfometría del canal Upsala se debe principalmente al gran trabajo erosivo del hielo glaciar, sobre litologías débiles, como las pizarras, y sobre los valles Moyano y Norte, donde la litología se caracteriza por vulcanitas (Lo Vecchio et al., 2016).

El CHPS está ubicado en el eje de los vientos del oeste (Naruse y Casassa, 1985), recibiendo sobre su margen occidental un fuerte aumento de precipitación pluvial y de nieve debido al efecto orográfico (Schaefer et al., 2015). La Patagonia Occidental presenta un modesto ciclo estacional y una precipitación media anual de $\sim 6.400 \mathrm{~mm}$ en los sectores más elevados del CHPS (Garreaud et al., 2013, 2014), y una alta acumulación de nieve medida de hasta 15,4 m3 (m eq, $\mathrm{a}^{-1}$ ) (Schaefer et al., 2015). La temperatura media anual es de $\sim 6^{\circ} \mathrm{C}$ (Carrasco et al., 2002), coexistiendo bosque nativo de Nothofagus junto al hielo en la periferia de los frentes de los glaciares. 


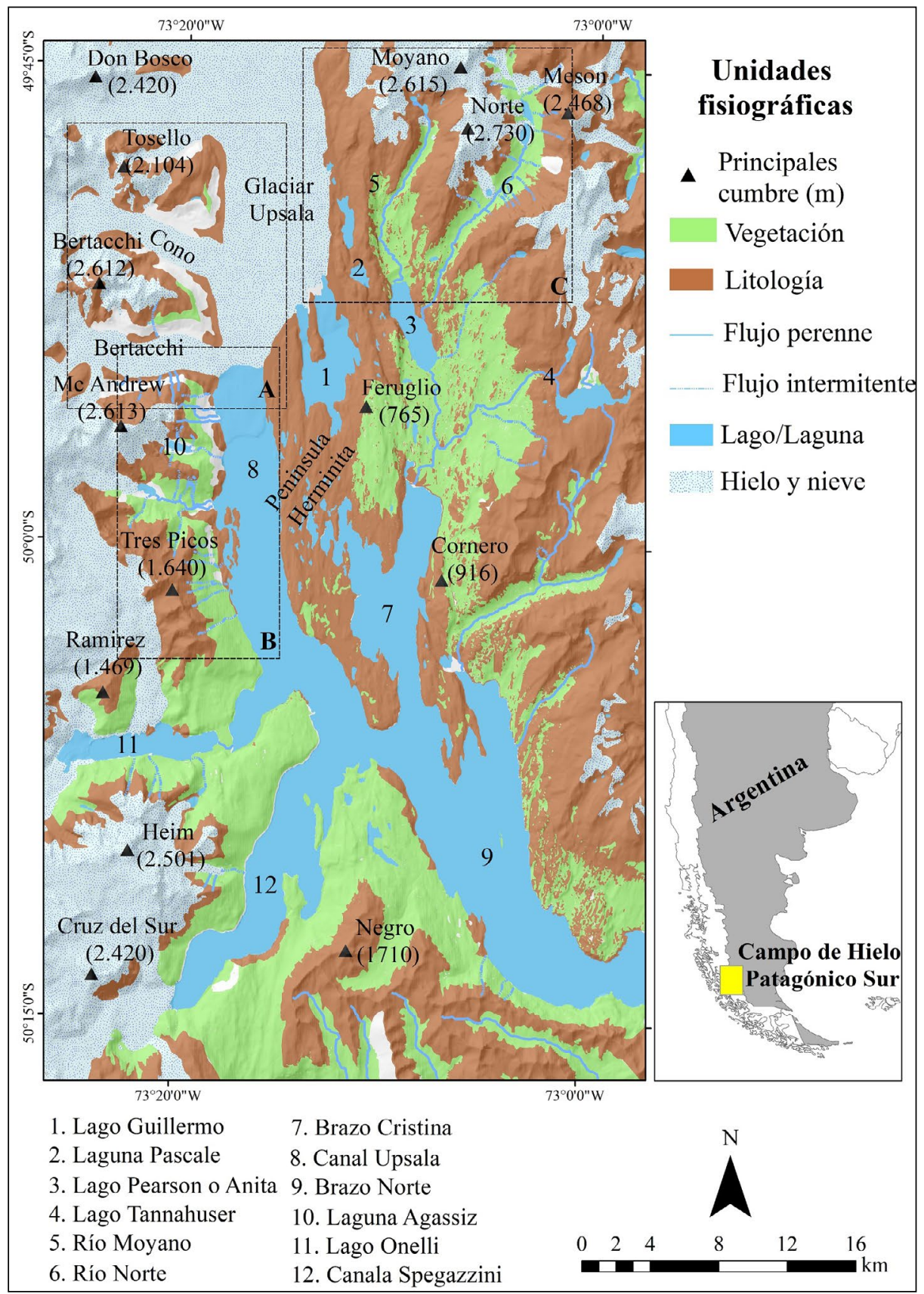

Figura 1. Área de estudio, Brazo Norte del lago Argentino, Campo de Hielo Patagónico Sur, Santa Cruz, Argentina con las unidades fisiográficas. Los recuadros con líneas punteadas corresponden a las áreas de estudio mostradas en la figura 2 (A), figura 3 (B) y figura 4 (C), respectivamente. 


\section{Material y Métodos}

\subsection{Geomorfología paraglacial}

Se ha demostrado que algunos tipos de movimiento de masas rápido pueden identificarse con precisión utilizando una combinación de imágenes de satélite de alta resolución y modelos de elevación digitales (Barlow et al., 2009). La detección e identificación de las geoformas, asociadas a inestabilidad y erosión de laderas, se realizó mediante el uso de sensores remotos ópticos. Las imágenes se trabajaron a escala media 1:25.000, con el software Quantum GIS 2.18.19 (www.qgis.or), a través de técnicas de fotointerpretación. Estas representaciones requieren escalas de mayor detalle y, por lo general, no inferiores a 1:25.000, de tal manera que se detecten las formas y los depósitos relacionados con los procesos morfo-evolutivos que afectan o han afectado, por ejemplo, a las laderas, valles, planicies y costas (Singhroy, 2002). Las imágenes de satélite utilizadas fueron Landsat 7 ETM+, nivel L1T, 30 m, del día 01 de abril de 2017 (ID: LE72310952017091ASN00); ASTER, L1A, 15 m, del día 25 de enero de 2013 (ID: AST_L1A_00301252013143719_01262013114303) y 02 de abril de 2014 (ID: AST_L1A_00304022014143734_0403 2014030825); e imágenes de alta resolución disponibles en Google Earth (www.google.com.ar/intl/es/earth/). Las escenas no contienen nieve estacional significativa y carecen de nubes en las áreas de interés.

La detección de las características geomorfológicas se realizó utilizando combinaciones de bandas de las imágenes para lograr un mayor detalle. En el caso de Landsat 7 ETM+, se combinaron las bandas 542 (RGB) para detectar zonas con deslizamientos (Paolini et al., 2002; Petley et al., 2002) y la hidrografía del área. La combinación 432 para una óptima sensibilidad a la vegetación verde, lo que favoreció poder observar las áreas de las laderas con pérdida de material reciente. Por último, la combinación 321, que exhibe el color natural para distinguir la litología es, además, óptima para la detección de deslizamientos en zonas boscosas (Estrada y Kohiyama, 2001). Estas combinaciones sirvieron para verificar los resultados obtenidos de vegetación y litología (Lo Vecchio et al., 2016). Para detectar con mayor detalle las diversas geoformas, se utilizó la banda 8 pancromática (Landsat ETM+) e imágenes ASTER, ambas de 15 m de resolución. Las imágenes ASTER, L1A, se ortorectificaron a partir del Modelo Digital de Elevación (MDE) SRTM (Shuttle Radar Topography Mission) (Moragues et al., 2018). Las imágenes de satélite y el SRTM se adquirieron desde el portal Earth Explorer de USGS (United States Geological Survey, www.earthexplorer.usgs.gov). Todos los datos fueron proyectados al sistema UTM zona $18 \mathrm{~S}$.

Se detectaron unidades fisiográficas del área (principales cumbres, litología, morrenas terminales que represan lagos proglaciares, vegetación, hidrografía -glaciares, nieve, lagunas, lagos y flujos-), así como también geoformas paraglaciares, asociadas a procesos de inestabilidad y erosión, con el fin de comprender de manera general el comportamiento y dinámica del paisaje. También se cuantificó el área $\left(\mathrm{km}^{2}\right)$ que abarca cada una de las unidades fisiográficas, geoformas y procesos paraglaciares en el Brazo Norte del lago Argentino (ver más adelante la Tabla 2). De esta manera, se compara cuantitativamente la importancia del fenómeno paraglacial con las áreas aún cubiertas por hielo y, además, las unidades fisiográficas presentes en la zona. 
Tabla 1. Parámetros geomorfométricos.

\begin{tabular}{|l|l|}
\hline \multicolumn{1}{|c|}{ Parámetros del terreno } & \multicolumn{1}{c|}{ ¿Qué describen? } \\
\hline Elevación (m.s.n.m.) & $\begin{array}{l}\text { Indica la altura de un punto comparado con el nivel del mar. } \\
\text { Curvas de nivel cada 400m. }\end{array}$ \\
\hline Pendiente (grados) & $\begin{array}{l}\text { Indica la magnitud del gradiente, lo que condiciona la velocidad } \\
\text { del flujo. }\end{array}$ \\
\hline Orientación (grados) & Orientación de la ladera. Representa la dirección del flujo. \\
\hline $\begin{array}{l}\text { Curvatura de Perfil (cóncavo- } \\
\text { convexo) }\end{array}$ & $\begin{array}{l}\text { Indica la dirección de la pendiente máxima. Áreas de acel- } \\
\text { eración (cóncavo, valores positivos) o desaceleración del flujo } \\
\text { (convexo, valores negativos). }\end{array}$ \\
\hline Rugosidad (índice 0-1) & $\begin{array}{l}\text { Características de irregularidad o accidentalidad del terreno, } \\
\text { valores cercanos a 1 el terreno es más irregular. }\end{array}$ \\
\hline
\end{tabular}

Tabla 2. Áreas en $\mathrm{km}^{2}$ de las unidades fisiográficas, geoformas paraglaciares (remoción en masa y erosión) y formaciones geológicas del área del brazo Norte del lago Argentino.

\begin{tabular}{|l|c|}
\hline Unidades fisiográficas & Área $\mathbf{~ k m}^{2}$ \\
\hline Hielo y nieve & $1.272,51$ \\
\hline Vegetación & 399,53 \\
\hline Cuerpos de agua (lago y lagunas) & 335,76 \\
\hline Morena terminal & 4,07 \\
\hline Geoforma de remoción en masa y erosión & \\
\hline Material morrénico colapsado & 18,51 \\
\hline Cono de derrubio fósil & 2,65 \\
\hline Deslizamiento & 1,61 \\
\hline Depósito de crecimiento & 1,32 \\
\hline Abanico aluvial & 1,2 \\
\hline Abanico aluvial fósil & 0,85 \\
\hline Cono de derrubio & 0,45 \\
\hline Coladas de piedras & 0,5 \\
\hline Rocas aborregadas & 0,29 \\
\hline Formaciones geológicas & \\
\hline Complejo El Quemado & 848,31 \\
\hline Fm. Río Mayer & 278,45 \\
\hline Fm. Bahía La Lancha & 140,02 \\
\hline Fm. Cerro El Toro & 113,83 \\
\hline
\end{tabular}

\subsection{Parámetros geomorfométricos y factores estimados}

Las causas de los movimientos de ladera pueden dividirse en factores que contribuyen a aumentar la tensión de cizallamiento y factores que contribuyen a una resistencia al cizallamiento baja o reducida (Varnes, 1978; Cruden y Varnes, 1996). Estos factores se dividen en condicionantes y desencadenantes. Los factores condicionantes, relacionados con las propiedades internas, incluyen características geomórfológicas y geológicas, 
afloramientos rocosos, tipos de rocas y cobertura vegetal de las laderas (Zêzere et al., 1999; Fernandes et al., 2004; Cubito et al., 2005; Moreiras, 2005). Los factores desencadenantes de los deslizamientos, que se introducen al sistema, incluyen la meteorización, los terremotos, las lluvias y el derretimiento de la nieve (Kawabata y Bandibas, 2009). Por esta razón, se realiza un análisis basado en la detección de estos factores a través de sensores remotos, referencias bibliográficas, observación in situ del terreno y parámetros morfométricos.

Para proporcionar el contexto topográfico y análisis del terreno (parámetros morfométricos), se utilizó el MDE ALOS PALSAR (Phased Arraytype L-band Synthetic Aperture Radar), $12.5 \mathrm{~m}$ de resolución, obtenido de la plataforma Alaska Satellite Facility (https://www.asf.alaska.edu/sar-data/palsar/). Los parámetros morfométricos, basados en el análisis de las propiedades geométricas de la superficie del terreno, se obtuvieron mediante funciones matemáticas implementadas en ventanas móviles (3x3), que se aplicaron al MDE (Hartemink y McBratney, 2009), derivados de los software SAGA GIS v2.10 (www.saga-gis.org) y QGIS. Basándonos en Franklin y Peddle (1987) se calcularon cinco parámetros básicos, relacionados con la topografía y geometría de las laderas: elevación, pendiente, orientación, curvatura (de perfil) y rugosidad del terreno (Tabla 1). Estos parámetros fueron desarrollados siguiendo los criterios y conceptos de Hartemink y McBratney (2009). Cabe aclarar que existen dos tipos de curvatura del terreno, de plano y de perfil; en el presente estudio, se selecciona la curvatura de perfil, ya que nuestro interés es conocer la forma de la vertiente que acelera y desacelera los flujos intervinientes.

\section{Resultados}

\subsection{Geomorfología paraglacial}

El área del brazo Norte del lago Argentino presenta una variabilidad de unidades fisiográficas (ver Fig.1) y geomorfológicas, combinando procesos glaciares y paraglaciales. Las laderas que muestran mayores procesos paraglaciales, producto de remoción en masa, son las que se encuentran en contacto directo con el glaciar Upsala y sus glaciares tributarios Bertacchi y Cono (Fig. 2), así como también las "abandonadas" recientemente por el hielo, como es la ladera occidental del canal Upsala (Fig. 3). Otra de las zonas con procesos paraglaciales son los valles Moyano y Norte (Fig. 4).

La Fig. 1 muestra el mapa general de localización, junto con las grandes unidades fisiográficas que ocupan el área. Geomorfológicamente, el Brazo Norte del lago Argentino puede definirse como una zona que presenta una combinación de procesos de remoción en masa y erosión, que han dado lugar a cambios superficiales en las laderas. Las geoformas que se reconocen en este sector corresponden a deslizamientos, solifluxión, superficies aborregadas, material morrénico colapsado, coladas de piedras, conos de derrubios, abanicos aluviales, depósitos de crecidas; y accidentes geográficos asociados, tales como zonas de arranque, talud, escarpes y grietas de tensión. Las laderas en las que no existe indicio de inestabilidad o algún evento de degradación de la superficie, se encuentran tapizadas por vegetación o litologías más resistentes. 


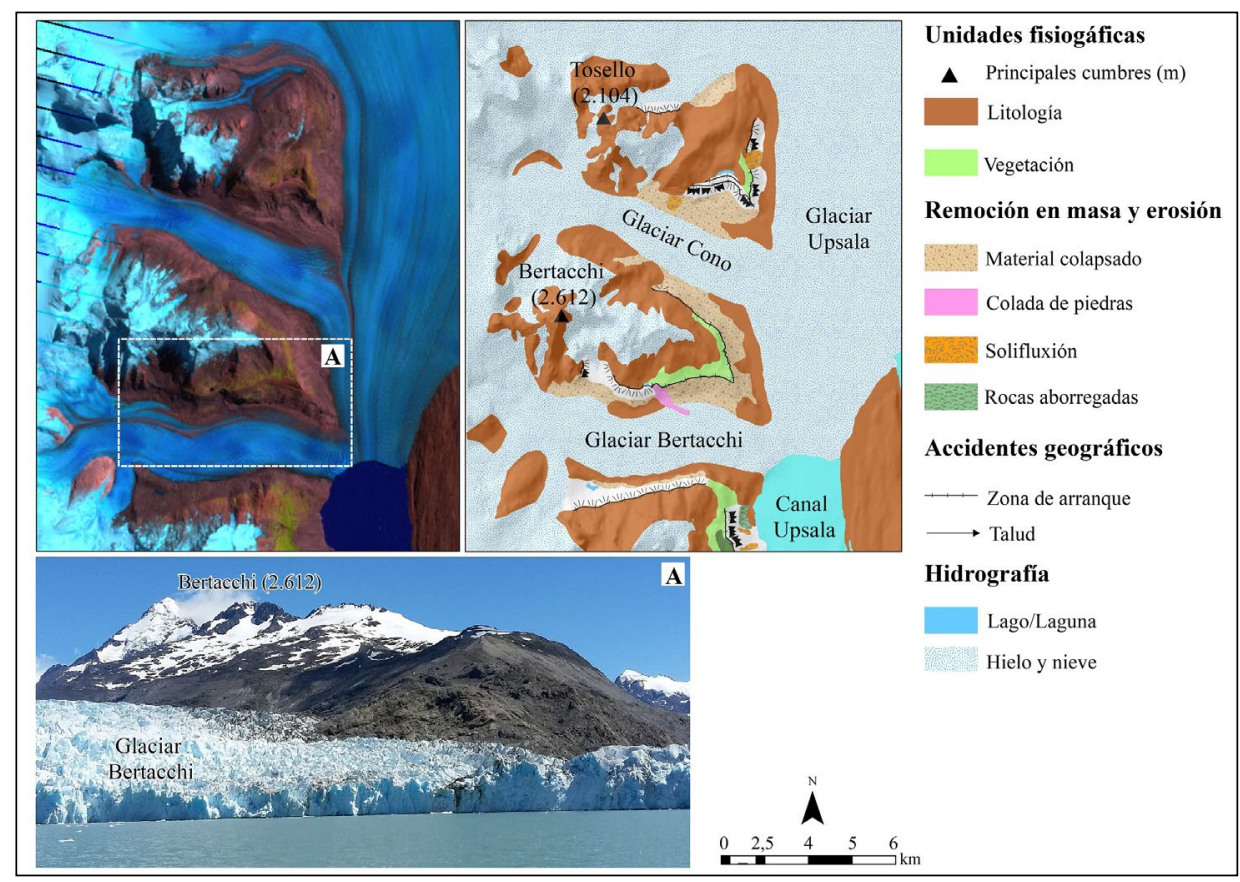

Figura 2. Superior izq.: área de los glaciares tributarios Cono y Bertacchi en base a imagen Landsat ETM+(542), en recuadro con líneas punteadas se muestra la región correspondiente a la fotografía (A) (fotografía tomada desde el canal Upsala hacia la ladera norte del glaciar Bertacchi). Superior der.: geomorfología paraglacial de las laderas de los glaciares tributarios.

Las laderas de los glaciares tributarios (Bertacchi y Cono) (ver Fig. 1A) presentan mayor área de material morrénico colapsado que el resto de los procesos de remoción en masa presentes (Tabla 2). Además, se evidencian las pendientes cubiertas de derrubios y una colada de piedras de gran magnitud y activa sobre el glaciar Bertacchi (Fig. 2), recientemente deglaciada, que ha sido transportada con el fluir del hielo. Existen geoformas de coladas de piedras inactivas, de menores dimensiones y funcionalidad; cabe destacar que éstas no son representadas gráficamente debido a la escala espacial de las imágenes utilizadas.

La Figura 3, muestra una degradación del material de la ladera, dependiendo de la elevación (en metros) del límite superior del material morrénico. Sobre el canal Upsala los sectores de mayor altura de las laderas $(800-1.000 \mathrm{~m})$ no presentan signos de inestabilidad, sino una densa cubierta de vegetación. A partir de los $\sim 600 \mathrm{~m}$, se evidencia la inestabilidad con predominio de eventos puntuales como la presencia de un deslizamiento de grandes magnitudes, caída de rocas, estructuras que denotan desplazamientos como las ondulaciones, solifluxión, y evidencia de actividad con las grietas de tensión cubiertas por la vegetación. Esta ladera presenta geoformas que denotan la dinámica paraglacial anterior, con depósitos de morrenas cuaternarias estabilizadas, conos de derrubios y abanicos aluviales que forman un talud continuo, fosilizados y fijados por la vegetación (Fig. 3). 


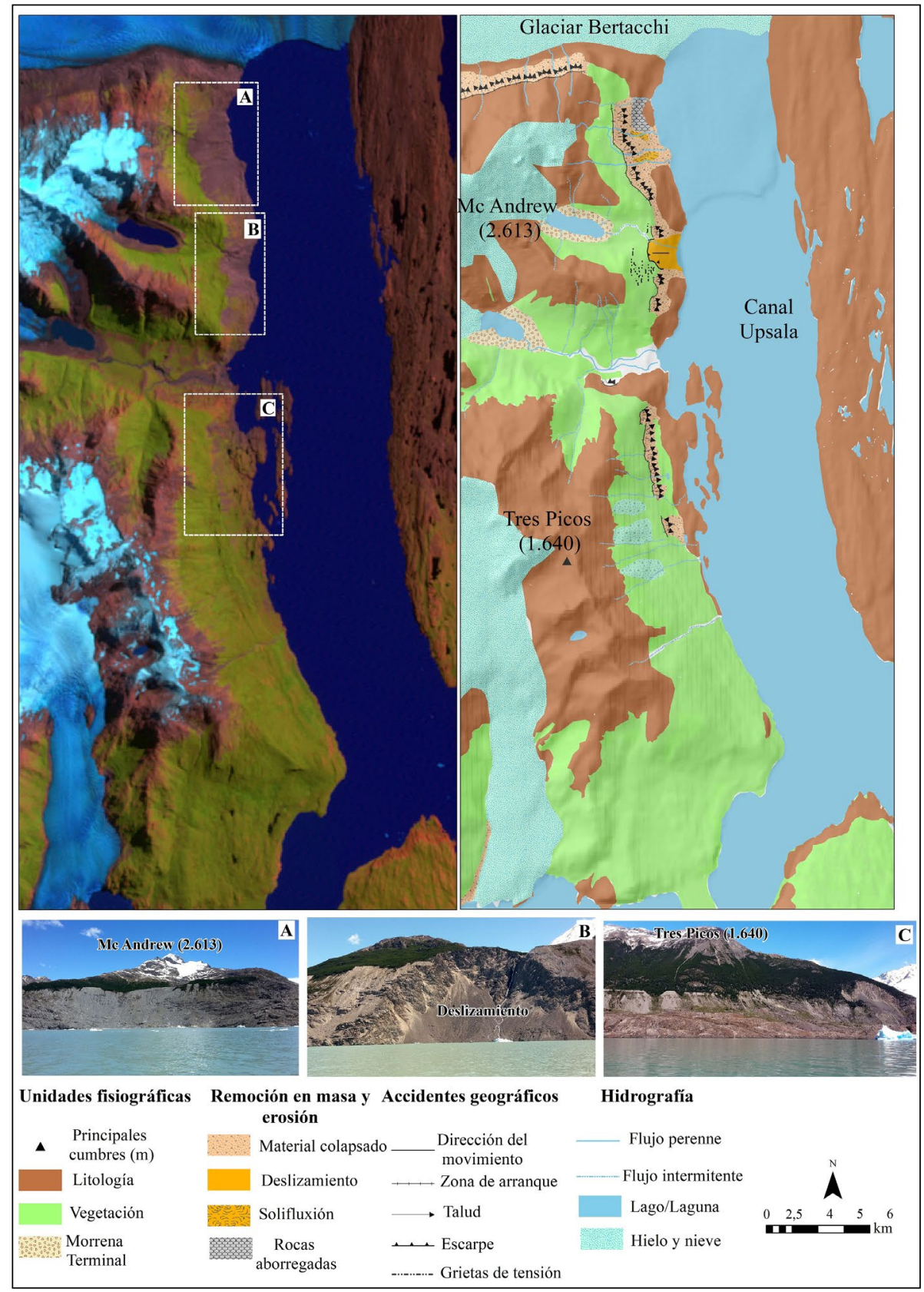

Figura 3. Superior izq.: área de la ladera occidental del canal Upsala en base a imagen Landsat ETM+(542), en recuadro con líneas punteadas se muestra la región correspondiente a las fotografias A) Ladera occidental, B) Deslizamiento Agassiz, C) Morrena con signo de colapso (Moragues et al., 2019) (fotografías tomadas desde el canal Upsala hacia la ladera occidental). Superior der.: geomorfología paraglacial de la ladera occidental del canal Upsala. 


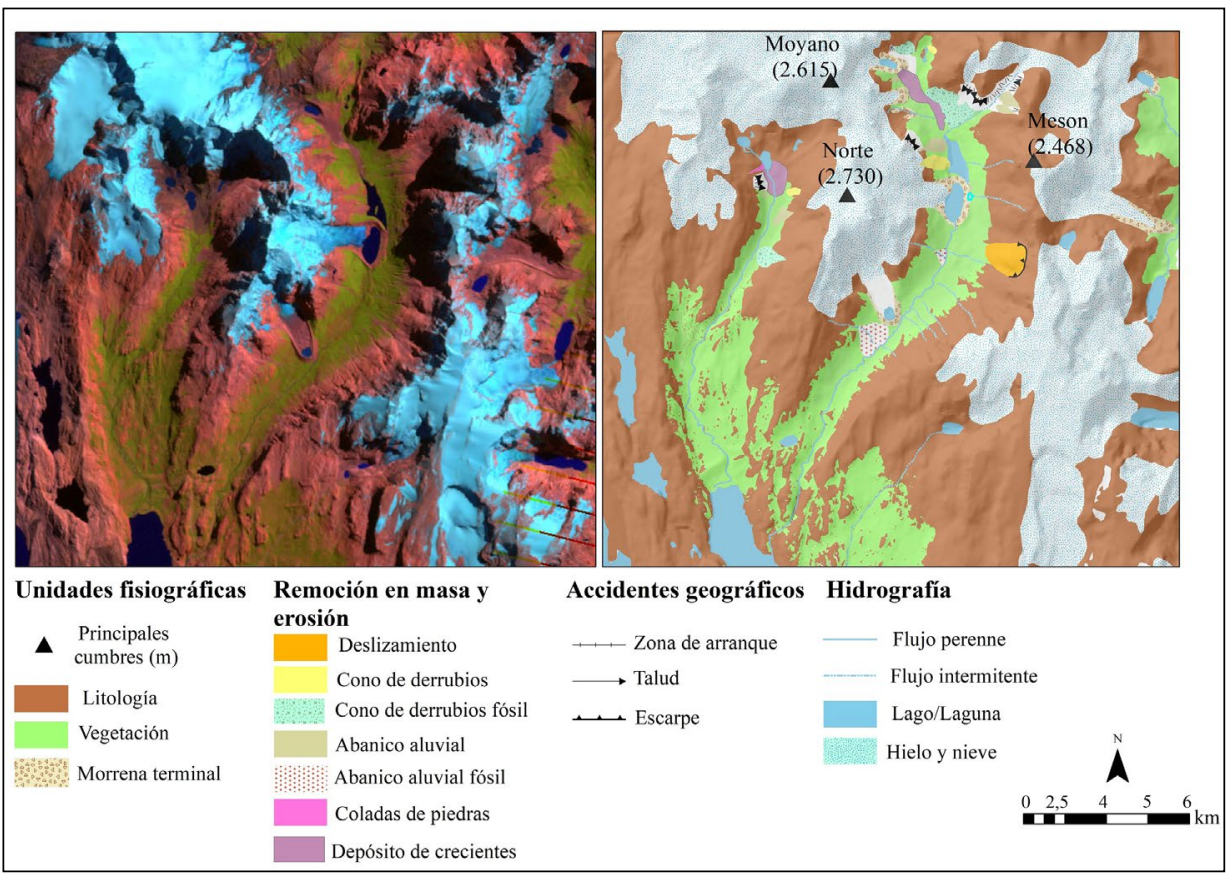

Figura 4. Izq.: área de los valles Moyano y Norte en base a imagen Landsat ETM+ (542). Der.: geomorfología paraglacial de las laderas de los respectivos valles.

Los valles Moyano y Norte también presentan geoformas gravitacionales y de erosión fluvial, como zonas de arranque con talud, un deslizamiento en la vertiente sur del valle Norte y conos de derrubios y abanicos aluviales (Fig. 4). Algunas lagunas proglaciares, formadas después de la retirada de los glaciares que descienden de las cimas Moyano $(2.615 \mathrm{~m})$, Norte $(2.730 \mathrm{~m})$ y Mesón $(2.468 \mathrm{~m})$ y represadas por morrenas terminales, presentan abanicos aluviales y conos de derrubios. En las cabeceras de ambos valles las lagunas proglaciares, han sufrido un colapso, generando depósitos de crecientes (Fig. 4). Destacan en ambos valles formas de conos de derrubios y abanicos aluviales fósiles, cubiertas y estabilizadas con vegetación, situadas en cotas altitudinales más bajas del valle (700-900 m) (Fig. 4), indicando la anterior dinámica paraglacial en respuesta a la retracción de los glaciares existentes en esos valles.

\subsection{Análisis del terreno: parámetros geomorfométricos y factores estimados}

\subsubsection{Factores condicionantes}

La presencia de depósitos morrénicos en el área es importante sobre las márgenes del canal Upsala, los glaciares tributarios Bertacchi y Cono y los valles que rodean la zona. El retiro del glaciar Upsala, ha dejado expuestas empinadas pendientes cubiertas de depósitos glaciogénicos, material poco consolidado, heterogéneo y altamente per- 
meable. Este material pertenece a tres sistemas morrénicos y acumulaciones proglaciares de las glaciaciones Herminita, Pearson I y II, depositados en el Holoceno (Malagnino y Strelin, 1992; Strelin et al., 2014). Poco después del último máximo glaciar, el cinturón de morrenas pasa por un área de más de $180 \mathrm{~m}$ por encima del lago Argentino. Las morrenas Pearson I y II están bien representadas a ambos lados del canal Upsala, éstas tienen hasta $6 \mathrm{~m}$ de altura (Strelin et al., 2014). Estas morrenas son las que se encuentran sometidas a estos procesos de inestabilidad y erosión sobre las laderas.

La pendiente de las laderas es de gran importancia, Dai y Lee (2002) destacaron que el aumento del gradiente de pendiente se correlaciona con una mayor probabilidad de inestabilidad. El ángulo crítico de inclinación en zonas montañosas, para que se generen eventos de remoción en masa, es de 30-32 (Clarke y Burbank, 2010; Tofelde et al., 2017). Los valles de la zona poseen pendientes entre $25^{\circ}$ y $48^{\circ}$, existiendo sitios cercanos al frente del glaciar Upsala que presentan pendientes de hasta $57^{\circ}$ (Fig. 5B), siendo valores propicios para que el material descienda por gravedad, y de esta manera se condiciona la velocidad del flujo.

La orientación de las laderas está relacionada con mayor o menor insolación (umbría o solana). La ladera occidental del canal Upsala presenta una orientación este-noreste (Fig. 5C), es decir, que se encuentra expuesta a mayor cantidad de horas de sol, lo que favorece la fusión de la nieve y saturación del material morrénico. Lo mismo ocurre en los valles Moyano y Norte, en los cuales las laderas se orientan hacia el este-sureste, exponiéndose al sol. Por el contrario, en dichos valles las pendientes oeste-noroeste, presentan menos signos de inestabilidad, debido a que la insolación posiblemente no permite la rápida fusión de la nieve (Fig. 5C).

Otro parámetro clave es el análisis del índice de rugosidad del terreno; las laderas presentan un índice con un rango que se extiende desde leve a elevado $(0,40$ a 0,65$)$ en aquellas zonas con procesos de inestabilidad. En las partes superiores las pendientes presentan valores de rugosidad elevados y extremos (0,68 a 0,89) (Fig. 5E).

Por otro lado, se evidencian taludes pendientes desde la zona superior de la ladera hacia el valle o el lago; las zonas de arranque se generan a $600-700$ m (Fig. 5A). Los valles Moyano y Norte también exhiben sectores de talud, pero en menor cantidad. Esto se debe también a la forma del terreno, es decir la curvatura de la pendiente. La ladera occidental del canal presenta en la zona media material colapsado con curvatura cóncava (valores positivos), es decir, que el flujo se acelera por la pendiente. Por el contrario, en las zonas bajas con afloramientos rocosos, la pendiente es convexa y la corriente de flujo se desacelera (Fig. 5D). Por ello, las diferencias entre las vertientes convexas y cóncavas en las laderas, radican en que la distribución de las pendientes de talud y las zonas de arranque estén situadas a alturas específicas.

El retroceso de los glaciares del área trae aparejada la relajación de las laderas y la progresiva pérdida del "sostén" que genera la lengua del glaciar sobre éstas. Esta distensión suele estar reflejada mediante la generación de grietas de tensión. Estas grietas en ocasiones son rellenadas por el agua caída en verano y la nieve de invierno, por expansión térmica y procesos de gelifluxión generando el ensanchamiento de las mismas (Winocur et al., 2015). A los 700-800 m se evidencian como signo de actividad grietas de tensión, ubicadas en la zona inferior de la laguna Agassiz (Figs. 3 y 6A), sitio donde se generó el deslizamiento rotacional Agassiz en febrero del 2013 (Fig. 6B) (Moragues et al., 2019). 


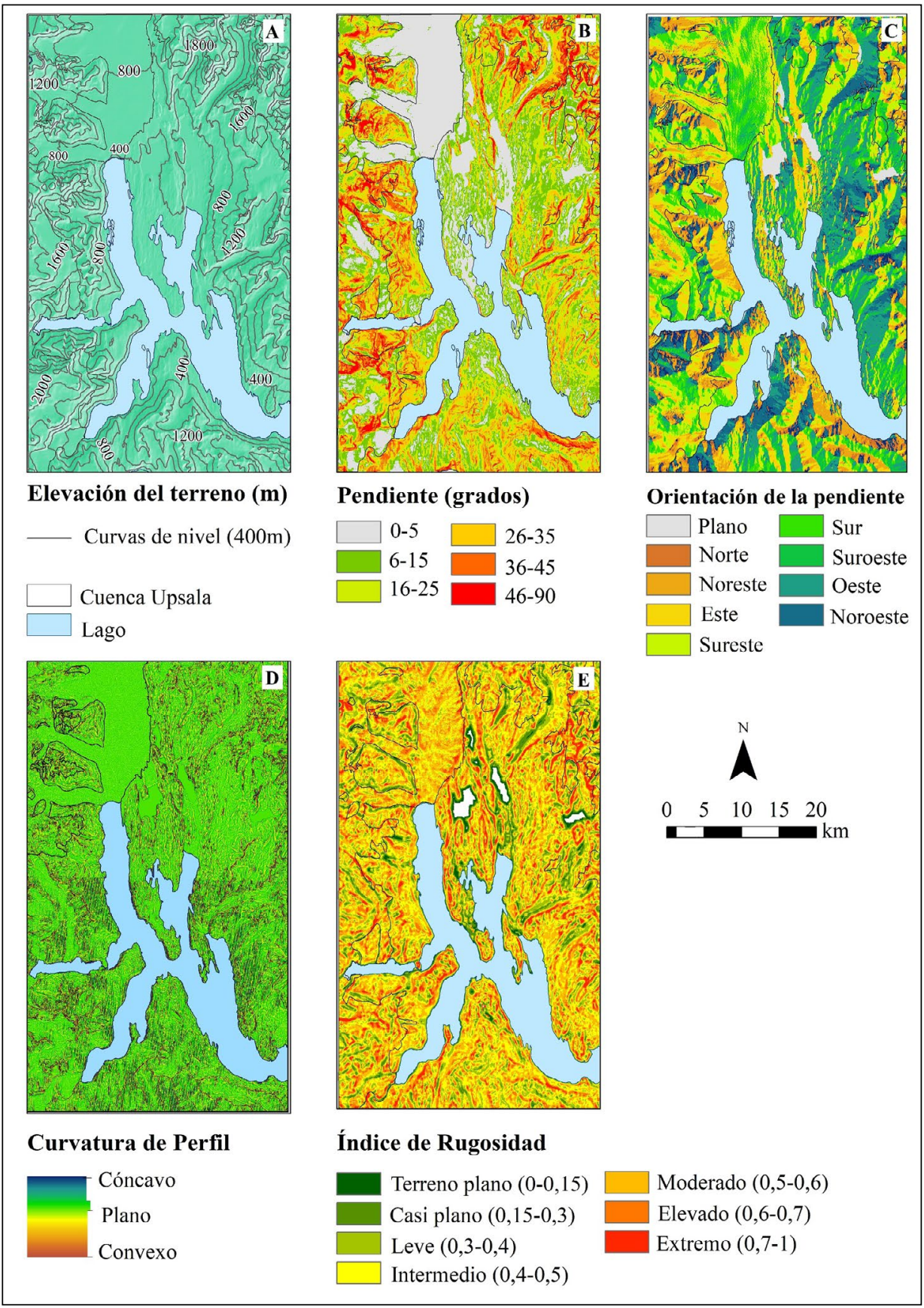

Figura 5. Parámetros geomorfométricos del área de estudio, (A) Elevación del terreno con curvas de nivel cada $400 \mathrm{~m}$. (B) Pendientes del terreno en grados, (C) Orientación de las pendientes en grados, (D) Curvatura de perfil de las laderas,(E) Índice de rugosidad del terreno. 


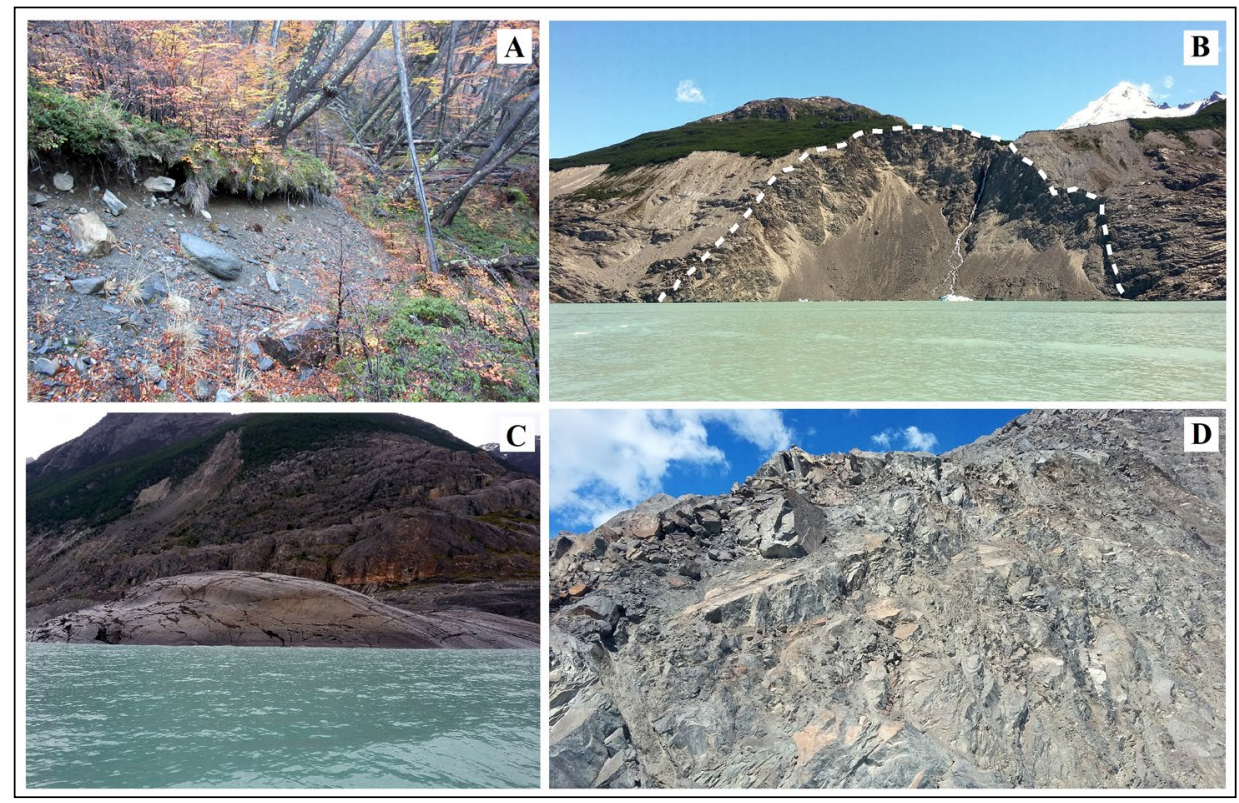

Figura 6. Ladera occidental del canal Upsala, (A) Grietas de tensión, vegetación orientados con el movimiento de reptación. (B) Deslizamiento Agassiz (línea punteada), con presencia de escorrentía subterránea y superficial. El contacto directo entre el material de la ladera y el pelo de agua del lago Argentino resulta evidente en la zona superior el bosque de Nothofagus. $(C)$ Rocas pulidas y aborregadas, formadas por la abrasión glaciar, indicando la dirección del flujo del glaciar Upsala. (D) Rocas meteorizadas de gran tamaño, ubicadas en el flanco derecho del deslizamiento Agassiz.

La Fig. 7 muestra las formaciones geológicas del área, representadas en base a Kraemer y Riccardi (1997) y Lo Vecchio et al. (2016). En el entorno del glaciar Upsala se evidencia un gran predominio de pizarras del Cretácico (Kraemer y Riccardi, 1997), en detrimento de otras litologías. Sin embargo, en las laderas occidentales del canal Upsala, de los glaciares tributarios Bertacchi y Cono, y de los valles Moyano y Norte, en los cuales se sitúan la mayoría de los procesos de inestabilidad y erosión (Fig. 7), predominan las vulcanitas del Complejo de El Quemado (CEQ), derivadas de depósitos glaciogénicos (Lo Vecchio et al., 2016). Esta formación es la que mayor área cubre en la zona con $848,37 \mathrm{~km}^{2}$ (Tabla 2), cubriendo por completo la presencia de procesos de inestabilidad y degradación sobre el material morrénico y litología, en la ladera occidental del canal Upsala y las laderas de los valles Moyano y Norte. Esta litología aflora en las zonas bajas de la ladera en contacto con el lago Argentino (Fig. 1).

En algunos sectores la roca se encuentra pulida y aborregada, con lineamientos en sentido del flujo glaciar y libre de depósitos, a una altura $\sim 300 \mathrm{~m}$ sobre la ladera (Fig. 6C). Existen zonas con presencia de rocas que han sufrido meteorización, siendo disgregadas en diversos tamaños, desde pequeños clastos que se deslizan fácilmente por la ladera, hasta grandes rocas ubicadas en las zonas altas. El área que presenta grandes 
rocas meteorizadas, pertenecientes al CEQ, es la zona superior del flanco derecho del deslizamiento Agassiz (Fig. 6D), con grandes probabilidades de que se generen procesos gravitacionales. La Fm. Río Mayer, con predominio de pizarras de mayor fisilidad y segunda en extensión de área con $278,45 \mathrm{~km}^{2}$, en las inmediaciones de los glaciares tributarios, presenta también geoformas paraglaciares asociadas a la inestabilidad (Fig. 7). Por el contrario, las Fm. Bahía La Lancha y Cerro El Toro, no presentan procesos paraglaciares actuales. Este último, es una gran formación rocosa de baja altura (200-300 m) que se denomina península Herminita, con una extensión de 113,83 km² (Tabla 2).

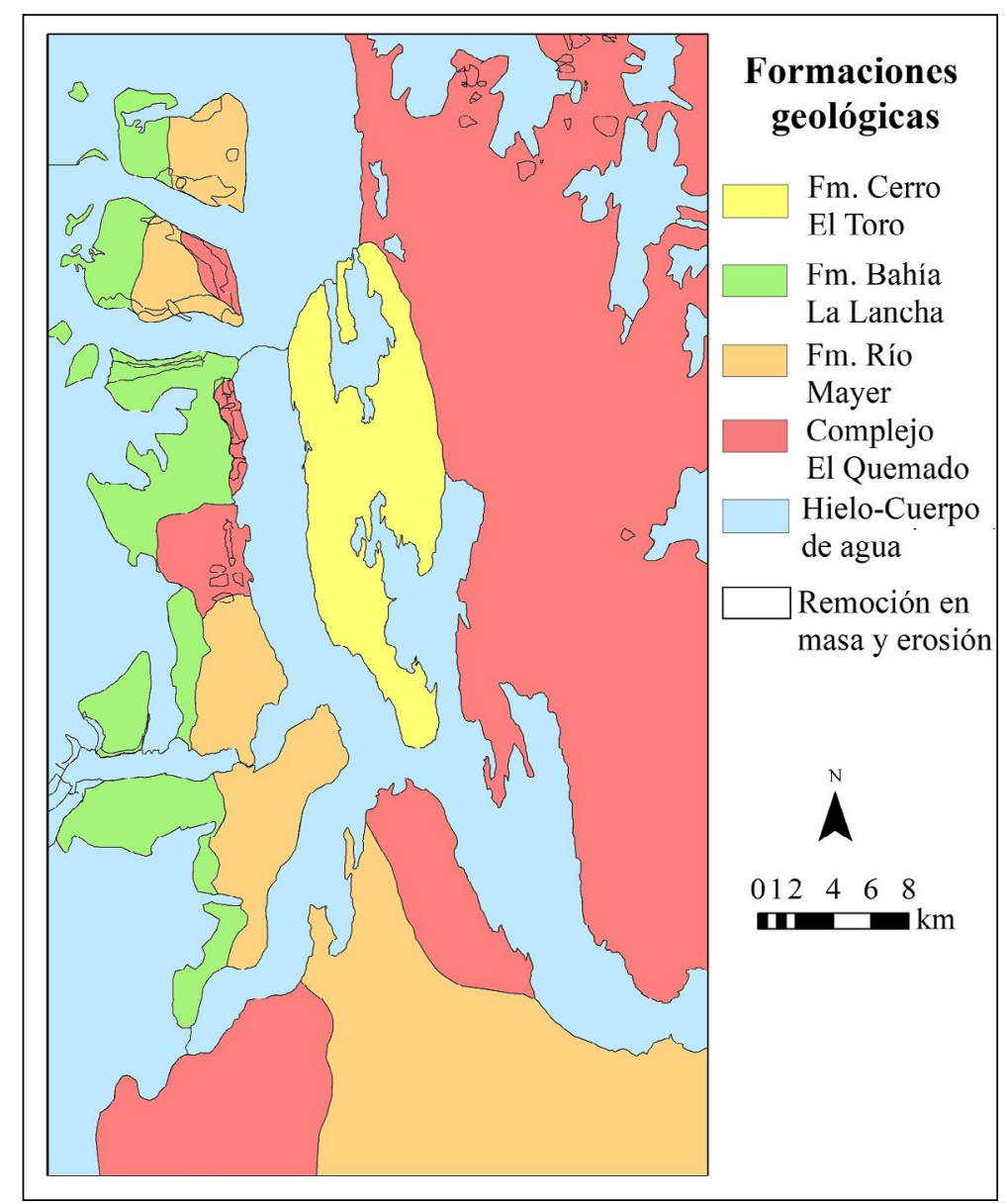

Figura 7. Formaciones geológicas representadas según Kraemer y Riccardi (1997) y Lo Vecchio et al. (2016).

La influencia de la vegetación en la estabilidad de las laderas, sobre todo en deslizamientos superficiales, es de gran importancia. Los depósitos de morrenas han dado lugar a la colonización vegetal (Figs. 1 y 6B), con un crecimiento casi continuo de gramíneas 
y árboles de Nothofagus (pumilio, betuloides, antarctica), bosque relicto maduro (Strelin et al., 2014; Echeverria et al., 2014) y estepa herbácea bajo el bosque. Sobre la ladera occidental, la altura máxima de vegetación se encuentra entre los 1.000-1.500 m. La masa boscosa continua determina la cobertura superficial de las laderas y evidencia más fácilmente las nuevas cicatrices de inestabilidad. Tiene el potencial de actuar de anclaje a causa de su sistema radicular, respondiendo al área de contacto entre las raíces y el suelo, lo cual supone que el material morrénico situado más allá del límite inferior radicular no sea "retenido". En algunas ocasiones, la vegetación puede significar una carga extra en la ladera, incrementando el esfuerzo de cizalla y la presión de agua en los poros, o también, permitir la percolación profunda de agua, y en efecto producir inestabilidad (Gutiérrez Elorza, 2008).

La Tabla 2 muestra las áreas $\left(\mathrm{km}^{2}\right)$ que cubren el relieve en la zona de interés, la extensión de la cobertura de hielo-nieve, vegetación y cuerpos de agua con mayor área $\left(2.008 \mathrm{~km}^{2}\right)$, en oposición a los procesos de remoción en masa y erosión que denotan una superficie de $26,93 \mathrm{~km}^{2}$. Destaca el material morrénico colapsado, que constituye la mayor superficie entre las geoformas de inestabilidad de laderas, al igual que los conos de derrubios fósiles sobre la ladera occidental y los valles Moyano y Norte. Si se compara con las áreas aún cubiertas de hielo, las geoformas paraglaciales cubren el 2,12\% de las áreas deglaciadas y el 6,74\% de las zonas vegetadas por bosque de Nothofagus y estepa herbácea. Si bien el porcentaje de las geoformas paraglaciales es menor en comparación con las unidades fisiográficas (hielo-nieve y vegetación), la presencia de estos procesos sobre las laderas "recientemente" deglaciadas resulta relevante.

\subsubsection{Factores desencadenantes}

Uno de los principales contribuyentes a la inestabilidad es el aporte de agua, ya sea de escurrimiento subterráneo o superficial, perenne e intermitente que satura el material. Puede tener lugar por aumento de la presión en los poros, lo que reduce la resistencia del material por hidratación, disminuye la cohesión y la fricción interna, y suele implicar el desplazamiento a lo largo de los planos de corte, aunque también pueden producir un flujo viscoso (Williams y Smith, 1989). Este aporte da como resultado, un aumento en el contenido de humedad del suelo. No solo se debe a la filtración por la precipitación, sino también a los flujos saturados del subsuelo que fluyen desde la cresta de la cuenca hacia la salida de la cuenca (Giuseppe et al., 2016).

La precipitación anual/estacional es un factor predominante en la ocurrencia de inestabilidad (Gariano y Guzzetti, 2016). Toda el área presenta grandes aportes de agua, con un régimen de precipitaciones que se ve afectado por la topografía. Las abundantes precipitaciones pluviales y de nieve, $\sim 6.400 \mathrm{~mm}$ anuales sobre el CHPS, teniendo en cuenta que presenta un fuerte gradiente de disminución de oeste a este (Garreaud et al., 2014), se distribuyen de forma relativamente uniforme a lo largo de todo el año (Bianchi y Cravero, 2010; Villalba et al., 2017), es decir, que las laderas de la zona están sometidas a un aporte de humedad constante por precipitaciones.

Otra contribución de agua son los lagos proglaciares represados por morrenas terminales, como es el caso de la laguna Agassiz, ubicada en la zona alta de la ladera 
occidental del canal Upsala o las lagunas ubicadas en el valle Norte (Fig. 1). No solo contribuye con agua superficial, sino también con escurrimiento subterráneo (Fig. 7B), hidratando el material permeable. El agua producto de fusión nívea, generada por el aumento de temperatura en verano, se infiltra y recorre las laderas desde las zonas altas generando flujos intermitentes (Fig. 1). Este aporte extra de agua aumenta las posibilidades de que procesos gravitacionales se activen en la zona.

El rápido descenso del nivel de agua en las costas colindantes a las laderas puede desencadenar inestabilidad (Huang et al., 2017). Según Richter et al. (2016), el lago Argentino tiene variaciones en el nivel del agua y corresponde a un periodo anual, con una amplitud de $\sim 1.2 \mathrm{~m}$, alcanzando su máximo en marzo, al final del verano austral y un mínimo en octubre. Esto puede incidir en la ladera occidental del canal Upsala, ya que tienen un contacto directo con el lago, tanto en el material morrénico como en la litología aflorante (Fig. 6B).

El cambio de temperatura influye en la inestabilidad (Gariano y Guzzetti, 2016), pero la de mayor influencia es el aumento de la temperatura media del aire (Sidle y Ochiai, 2006). En el área la temperatura media anual oscila entre $3^{\circ} \mathrm{C}$ en julio y $12^{\circ} \mathrm{C}$ en enero (Villalba et al., 2017). El cambio de la temperatura del aire condiciona la temperatura del suelo, que influye en la inestabilidad de la pendiente (Shibasaki et al., 2016), cuanto más extremas sean, mayor será su influencia sobre los ciclos de humedad-sequedad del suelo. Estos cambios originan procesos de expansión y contracción de los poros del terreno, con los consiguientes efectos sobre su grado de esponjamiento y saturación. La amplitud térmica diurna y estacional que existe en esta zona genera este efecto sobre el material de las laderas, permitiendo posibles colapsos gravitacionales.

La actividad sísmica es otro de los factores disparadores de la inestabilidad (Keefer, 1984). Las fallas activas aumentan la susceptibilidad a estos procesos, ya que las rocas y el material suelto que se encuentran cerca de la falla son más débiles, debido a la onda de vibración (Leir et al., 2004). En el área aún no existen registros oficiales de mediciones sísmicas, pero si se encuentra en un sistema de fallas activas. Según Kraemer y Riccardi (1997), el canal Upsala y los valles Moyano y Norte son recorridos por fallas inversas activas, que pueden generar movimientos sísmicos en la zona, causando posibles movimientos de ladera.

\section{Discusión}

\subsection{Relación entre la dinámica glaciar y los procesos paraglaciales}

Los procesos de inestabilidad de laderas (deslizamientos, avalanchas de rocas, coladas de piedras, etc.) pueden generarse en zonas de montaña recientemente abandonadas por glaciares (Jarman, 2006; Hewitt et al., 2008; Kellerer-Pirklbauer et al., 2010; Owen et al., 2010; Ballantyne y Stone, 2013; Kovanen y Slaymaker, 2015, entre otros). Todas las formas de respuesta paraglacial se sustentan en un único elemento común: que la deglaciación ha dado lugar a la exposición de fuentes sedimentarias inestables o metaestables, que posteriormente se liberan y reelaboran mediante una amplia variedad y combinación de procesos a diferentes escalas de tiempo (Ballantyne, 2015). 
El CHPS, presenta grandes extensiones cubiertas de hielo que en las últimas décadas ha sufrido pérdida de masa y rápido retiro de los frentes de los glaciares (Glasser et al., 2011; Willis et al., 2012, entre otros). El glaciar Upsala, principal cuerpo de hielo del área, y sus glaciares tributarios no han sido la excepción (Naruse y Skvarca, 2000; Sakakibara y Sugiyama, 2014; Moragues et al., 2018; Foresta et al., 2018; entre otros). Es uno de los glaciares templados más dinámicos (Sakakibara et al., 2013), que presenta una combinación de procesos y mecanismos que lo convierten en un glaciar altamente activo debido a su rápido retroceso frontal, variaciones en la velocidad superficial, cambios en la ablación y balance de masa, y una elevada tasa de calving. Desde finales del siglo XX hasta el presente, ha sufrido una alta tasa de retracción frontal (Moragues et al., 2018), favoreciendo la actividad paraglacial sobre las laderas de los valles que lo circundan.

Según Moragues et al. (2019), los procesos de glaciación y deglaciación modificaron las tensiones en la estabilidad de las laderas y generaron procesos de inestabilidad, principalmente en la ladera occidental del canal Upsala. Se demuestra estadísticamente que las áreas de estudio seleccionadas presentan movimientos en el periodo 2001-2015 y que existe una relación directa entre el abandono del hielo sobre la ladera y la activación del movimiento sobre el material morrénico. Situaciones similares se dan, entre muchas otras, en las montañas de Hindukush y Karakoram (Los Himalayas) (Iturrizaga, 2008), en el Valle Fox, Nueva Zelanda, con el retroceso del glaciar Fox (McColl et al., 2017), en los cuales se han generado e identificado procesos paraglaciales que actúan como un agente significativo en el sistema geomorfológico, producto de la desglaciación, generando así procesos de desestabilización de las laderas de los sedimentos glaciogénicos superficiales, cercanos a los frentes de los glaciares (McColl et al., 2017).

La posición actual de las geoformas fósiles, conos de derrubios y abanicos aluviales (Fig. 3), alejadas del actual frente del glaciar Upsala, puede inferir en la relación existente entre el contacto del hielo y los procesos de inestabilidad paraglacial antiguos, ya que el glaciar ocupaba la ladera en ese sector para la década del '40 (Moragues et al., 2018). Las geoformas se encuentran fosilizadas y estabilizadas por la vegetación, denso bosque de Nothofagus, incidiendo de esta manera en que la ladera presente una dinámica paraglacial anterior. La colonización vegetal es una respuesta a la estabilización de la superficie del suelo (Mercier et al., 2009). Lo mismo ocurre con las laderas de los valles Moyano y Norte, pero con la retracción del hielo de glaciares de menores magnitudes.

\subsection{Influencia de los factores interviniente en los procesos paraglaciales}

Las geoformas paraglaciales se encuentran generadas e influenciadas por la combinación de varios factores, condicionados a su vez por parámetros morfométricos del terreno, variando según el área montañosa de interés (Curry et al., 2006; Johnson et al., 2007; Barlow et al., 2009; Kellerer-Pirklbauer et al., 2010; McColl, 2012; Feuillet et al., 2014; Santos-González et al., 2018, entre otros).

Actualmente en el Brazo Norte, los procesos geomorfológicos paraglaciares, poseen la influencia de varios factores (condicionantes y desencadenantes) como así también de parámetros morfométricos, provocando alteraciones en las laderas. Si bien todos 
ellos aportan y varían en la génesis de las geoformas paraglaciares, cabe destacar que la contribución de los diversos factores varía en el espacio a escala local (Feuillet et al., 2014). Uno de los principales factores que afecta a la estabilidad de las laderas en un ambiente paraglacial es el topográfico (Ryder, 1971b; Curry et al., 2006; Johnson et al., 2007; Barlow et al., 2009; Feuillet et al., 2014; Santos González et al., 2018). Sobre el Brazo Norte existe una influencia indiscutible del factor topográfico con pendientes mayores de $30^{\circ}$, situados en cotas altitudinales de 700-800 m para las laderas de los glaciares tributarios y valles Moyano y Norte, y 200-400 m para la ladera occidental del canal y un predominio de orientación de este-noreste. El factor litológico condiciona la presencia de estos eventos paraglaciales (Johnson et al., 2007; Barlow et al., 2009; Feuillet et al., 2014; Santos-González et al., 2018), siendo la formación geológica del Complejo El Quemado donde mayor cantidad de geoformas se han generado, formada por rocas piroclásticas de naturaleza volcánica. Como en todo ambiente glaciar o recientemente deglaciado, la presencia de morrenas laterales sobre las laderas y la pérdida del sostén del hielo sobre el material, influyen en estos eventos paraglaciales (Iturrizaga, 2008; Barlow et al., 2009; Curry et al., 2006; entre otros). De esta manera, aparecen mayor cantidad de estos procesos de inestabilidad en las laderas "recientemente" deglaciadas y geoformas fósiles en las actualmente "estabilizadas" por la vegetación. Por último, el aporte de agua por precipitaciones y deshielo (Allen et al., 2016) es el factor desencadenante más importante en el desarrollo de la dinámica paraglacial en el área.

Según Kellerer-Pirklbauer et al. (2010), los cambios morfológicos de las laderas por retroceso glaciar pueden ser: (i) ajustes del material de la ladera en forma lenta o de reptación, como sagging/sackung o de extensión lateral (Kääb, 2002; Matsuoka y Abe, 2002; Jarman, 2006; Hewitt et al., 2008, entre otros); (ii) La ocurrencia de catastróficos desprendimientos de roca de las laderas, deslizamientos de grandes rocas y avalanchas (Abele, 1974; Ballantyne, 2002; Hewitt, 2009; Cave y Ballantyne, 2016, entre otros), o por (iii) modificación de pendientes cubiertas de detritus, canales de coladas de piedras y procesos relacionados (Ballantyne y Benn, 1994; Haeberli et al., 1999; Curry, 2000; Reid y Evans, 2016, entre otros). Teniendo en cuenta estos cambios morfológicos, el área de estudio se encuentra influenciada por: reajustes de movimientos lentos de reptación sobre la ladera occidental del canal Upsala (Fig. 3) producto del reciente retiro del glaciar homónimo; la eventual ocurrencia de desprendimientos de rocas sobre las aguas del canal Upsala (Fig. 7D) y sobre los glaciares tributarios Bertacchi y Cono; la cobertura de detritus sobre las laderas propensas a deslizarse y la presencia de una gran colada de piedras sobre la ladera del glaciar Bertacchi (Fig. 2), como así también la generación de deslizamientos del material morrénico circundante (Fig. 4 y 6B).

\section{Conclusiones}

La estabilidad de las laderas está condicionada por la acción simultánea de una serie de procesos y factores relacionados con la topografía y geometría de las laderas, hidrografía, hidrogeología, litología y clima, entre otros. La geomorfología de las laderas y los valles, son producto de intervenciones y reajustes que modelan el paisaje actual. El área del Brazo Norte del lago Argentino, es representativo de estos ambientes de reajustes 
paraglaciares contemporáneos, respondiendo a la relación existente entre el retroceso de los glaciares y los procesos de inestabilidad. Es decir, que la deglaciación de la zona resulta en la exposición y posterior generación de una variedad de procesos que conlleva a la inestabilidad del material morrénico depositado en las laderas.

Los procesos geomorfológicos paraglaciales, asociados a la inestabilidad de laderas en el Brazo Norte del lago Argentino, se encuentran influenciados por la combinación de: (i) parámetros morfométricos del terreno: elevaciones y pendientes pronunciadas aptas para generar procesos gravitacionales, orientaciones de las laderas expuestas al sol, curvaturas cóncavas del terreno que aceleran los flujos y rugosidad elevada del terreno; (ii) factores condicionantes, como grandes cantidades de depósitos morrénicos y litología expuesta a procesos de meteorización, la fuertes pendientes de las laderas e influencia de la vegetación; (iii) factores desencadenantes, entre ellos el aporte de agua subterránea y superficial por precipitaciones, deshielo y escurrimiento, aumentos estacionales de temperatura del aire y suelo y variación en el nivel del agua del lago.

La ocurrencia de estos procesos paraglaciales no se generó con la misma intensidad en todos los valles de la zona. Las laderas que presentan mayor cantidad de material morrénico, en este caso de morrenas laterales depositadas por los grandes cuerpos de hielo, son las que exhiben mayor cantidad de geoformas paraglaciales. Es el caso de la ladera occidental del canal Upsala, que se encuentra en contacto directo con los glaciares tributarios Bertacchi y Cono, y la de los valles Moyano y Norte. De esta manera, se posibilita un escenario potencialmente óptimo para desencadenar procesos de inestabilidad, generando un ambiente con reajustes paraglaciales. En síntesis, el área del Brazo Norte del lago Argentino puede ser entendida como un ambiente glacial en combinación con uno paraglacial, siendo ambos parte integral de la evolución del paisaje.

\section{Agradecimientos}

La investigación fue financiada por la Agencia Nacional de Ciencia y Tecnología de Argentina (PICTO 1995-2013) y Consejo Nacional de Investigaciones Científicas y Técnicas (CONICET, Argentina). Los autores desean agradecer a Administración de Parques Nacionales (APN) y Parque Nacional Los Glaciares de la Provincia de Santa Cruz, Argentina, a Andrés Lo Vecchio, Adalberto Ferlito y Paulina Vacaflor, por su colaboración durante las campañas a terreno y la preparación del manuscrito. Este estudio es parte de la tesis doctoral de la geógrafa Silvana Moragues.

\section{Referencias}

Abele, G. 1974. Bergstürze in den Alpen. IhreVerbreitung, Morphologie und Folgeerscheinungen. Wissenschaftliche Alpenvereinshefte 25, Munich.

Allen, S.K., Rastner, P., Arora, M., Huggel, C., Stoffel, M. 2016. Lake outburst and debris flow disaster at Kedarnath, June 2013: hydrometeorological triggering and topographic predisposition. Landslides 13 (6), 1479-1491. https://doi.org/10.1007/s10346-015-0584-3.

Aniya, M., Skvarca, P. 1992. Characteristics and variations of Upsala and Moreno glaciers, southern Patagonia. Bulletin of Glacier Research 10, 39-53. 
Aniya, M., Sato, H., Naruse, R., Skvarca, P., Casassa, G. 1996. The Use of Satellite and Airborne Imagery to Inventory Outlet Glaciers of the Southern Patagonia Icefield, South America. Photogrammetric Engineering \& Remote Sensing 62, 1361-1369.

Aniya, M., Sato, H., Naruse, R., Skvarca, P., Casassa, G. 1997. Recent glacier variations in the Southern Patagonia Icefield, South America. Arctic and Alpine Research 29 (1), 1-12. https:// doi.org/10.2307/1551831.

Aniya, M., Enomoto, H., Aoki, T., Matsumoto, T., Skvarca, P., Barcaza, G., Suzuki R, Sawagaki T., Sato, N., Isenko, E., Iwasaki, S., Sala, H., Fukuda, A., Satow, K., Naruse, R. 2007. Glaciological and geomorphological studies at Glaciar Exploradores, Hielo Patagonico Norte, and Glaciar Perito Moreno, Hielo Patagonico Sur, South America, during, 2003-2005 (GRPP03-05). Bulletin of Glaciological Research 24, 95-107. http://www.seppyo.org/bgr/ pdf/24/BGR24p95.pdf.

Aristizábal, E., Yokota, S. 2006. Geomorfología aplicada a la ocurrencia de deslizamientos en el Valle de Aburrá. Dyna 73 (149). https://www .redalyc.org/pdf/496/49614902.pdf.

Ballantyne, C.K., Benn, D.I. 1994. Paraglacial Slope Adjustment and Resedlmenfation following Recent Glacier Retreat, Fåbergstølsdalen, Norway, Arctic and Alpine Research 26 (3), 255 269. https://doi.org/10.2307/1551938.

Ballantyne, C.K. 2002. Paraglacial geomorphology. Quaternary Science Reviews 21, 1935-2017. https://doi.org/10.1016/S0277-3791(02)00005-7.

Ballantyne, C.K., Stone, J.O. 2013. Timing and periodicity of paraglacial rock-slope failures in the Scottish Highlands. Geomorphology 186, 150-161. https://doi.org/10.1016/j. geomorph.2012.12.030.

Barlow, J., Martin, Y., Franklin, S. 2009. Evaluating debris slide occurrence using digital data: paraglacial activity in Chilliwack Valley, British Columbia. Canadian Journal of Earth Sciences 46 (3), 181-191. https://doi.org/10.1139/E09-012.

Bianchi, A.R., Cravero, S.A. 2010. Atlas climático digital de la República Argentina. Instituto Nacional de Tecnología Agropecuaria. Centro Regional Salta-Jujuy. Estación Experimental Agropecuaria Salta. Programa Nacional Ecorregiones. Proyectos INTA Pneco, 1301, 33-34.

Caldenius, C.C. 1932. Las glaciaciones cuaternarias en la Patagonia y Tierra del Fuego. Dirección General de Minas y Geología, Publicación 95, Buenos Aires.

Carrasco, J., Casassa, G., Rivera, A. 2002. Meteorological and climatological aspects of the Southern Patagonian Ice Fields. In: G. Casassa, F. Sepúlveda, R. Sinclair (Eds.), The Patagonian Ice Fields, a Unique Natural Laboratory for Environmental and Climate Change Studies. Kluwer Academic/Plenum Publishers, New York, 29-41.

Cave, J.A.S., Ballantyne, C.K. 2016. Catastrophic Rock-Slope Failures in NW Scotland: Quantitative Analysis and Implications. Scottish Geographical Journal 132 (3-4), 185-209. https://doi.org/10.1080/14702541.2016.1156148.

Clarke, B., Burbank, D. 2010. Bedrock fracturing, threshold hillslopes, and limits to the magnitude of bedrock landslides. Earth and Planetary Science Letters 297, 577-586. https://doi. org/10.1016/j.epsl.2010.07.011.

Cruden, D.M., Varnes, D.J. 1996. Landslide types and processes. In: A.K. Turner, R.L. Schuster (Eds.), Landslides investigation and mitigation. Transportation research board, US National Research Council. Special Report 247, Washington, DC, Chapter 3, 36-75.

Cubito, A., Ferrara, V., Pappalardo, G. 2005. Landslide hazard in the Nebrodi Mountains (Northeastern Sicily). Geomorphology 66, 359-372. https://doi.org/10.1016/j. geomorph.2004.09.020.

Curry, A.M. 2000. Observations on the distribution of paraglacial reworking of glacigenic drift in western Norway. Norsk Geografisk Tidsskrift 54, 139-147. https://doi. org/10.1080/002919500448512. 
Curry, A.M., Cleasby, V., Zukowskyj, P. 2006. Paraglacial response of steep, sediment-mantled slopes to post-'Little Ice Age' glacier recession in the central Swiss Alps. Journal of Quaternary Science 21 (3), 211-225. https://doi.org/10.1002/jqs.954.

Dai, F.C., Lee, C.F. 2002. Landslide characteristics and slope instability modeling using GIS, Lantau Island, Hong Kong. Geomorphology 42 (3-4), 213-228. https://doi.org/10.1016/ S0169-555X(01)00087-3.

Echeverria, M.E., Sottile, G.D., Mancini, M.V. 2014. Nothofagus forest dynamics and palaeo environmental variations during the mid and late Holocene, in southwest Patagonia. The Holocene 24, 957-969. https://doi.org/10.1177/0959683614534742.

Estrada, M., Kohiyama, M. 2001. Detection of damage due to the 2001, El Salvador earthquake using Landsat images. Proceedings of $22^{\text {nd }}$ Asian Conference on Remote Sending, Singapore, 6.

Feuillet, T., Coquin, J., Mercier, D., Cossart, E., Decaulne, A., Jónsson, H.P., Sæmundsson, P. 2014. Focusing on the spatial non-stationarity of landslide predisposing factors in northern Iceland: Do paraglacial factors vary over space? Progress in Physical Geography 38 (3), 354377. https://doi.org/10.1177/0309133314528944.

Fernandes, N.F., Guimarães, R.F., Gomes, R.A.T., Vieira, B.C., Montgomery, D.R., Greenberg, H. 2004. Topographic controls of landslides in Rio de Janeiro: filed evidence and modeling. Catena 55, 163-181. https://doi.org/10.1016/S0341-8162(03)00115-2.

Fitzsimons, S.J. 1996. Paraglacial redistribution of glacial sediments in the Vestfold Hills, East Antarctica. Geomorphology 15, 93-108. https://doi.org/10.1016/0169-555X(95)00122-L.

Foresta, L., Gourmelen, N., Weissgerber, F., Nienow, P., Williams, J.J., Shepherd, A., Plummer, S. 2018. Heterogeneous and rapid ice loss over the Patagonian Ice Fields revealed by CryoSat-2 swath radar altimetry. Remote Sensing of Environment 211, 441-455. https://doi. org/10.1016/j.rse.2018.03.041.

Franklin, S.E., Peddle, D.R. 1987. Texture analysis of digital image data using spatial concurrence. Computers \& Geosciences 13 (3), 293-311. https://doi.org/10.1016/0098-3004(87)90047-1.

Gariano, S.L., Guzzetti, F. 2016. Landslides in a changing climate. Earth-Science Reviews 162, 227-252. https://doi.org/10.1016/j.earscirev.2016.08.011.

Garreaud, R., Lopez, P., Minvielle, M., Rojas, M. 2013. Large-scale control on the Patagonian climate. Journal of Climate 1, 215-230. https://doi.org/10.1175/JCLI-D-12-00001.1.

Garreaud, R.D., Nicora, M.G., Bürgesser, R.E., Ávila, E.E. 2014. Lightning in Western Patagonia. Journal of Geophysical Research: Atmospheres 119, 1-15. https://doi. org/10.1002/2013JD021160.

Giuseppe, F., Simoni, S., Godt, J.W., Lu, N., Rigon, R. 2016. Geomorphological control on variably saturated hillslope hydrology and slope instability. Water Resources Research 52, 4590-4607. https://doi.org/10.1002/2015WR017626.

Glasser, N.F., Jansson, K.N., Harrison, S., Rivera, A. 2005. Geomorphological evidence for variations of the North Patagonian Icefield during the Holocene. Geomorphology 71 (3), 263-277. https://doi.org/10.1016/j.geomorph.2005.02.003.

Glasser, N.F., Jansson, K.N., Harrison, S., Kleman, J. 2008. The glacial geomorphology and Pleistocene history of South America between $38^{\circ} \mathrm{S}$ and $56^{\circ} \mathrm{S}$. Quaternary Science Reviews 27, 365-390. https://doi.org/10.1016/j.quascirev.2007.11.011.

Glasser, N.F., Ghiglione, M.C. 2009. Structural, tectonic and glaciological controls on the evolution of fjord landscapes. Geomorphology 105 (3), 291-302. https://doi.org/10.1016/j. geomorph.2008.10.007.

Glasser, N.F., Harrison, S., Jansson, K., Anderson, K., Cowley, A. 2011. Global sea-level contribution from the Patagonian Icefields since the Little Ice Age maximum. Nature Geoscience 4, 303-307. https://doi.org/10.1038/ngeo1122. 
Gutiérrez-Elorza, M. 2008. Geomorfología. Madrid, Pearson Prentice Hall, 229-270.

Haeberli, W., Kääb, A., Hoelzle, M., Boesch, H., Funk, M., VonderMuehll, D., Keller, F. 1999. Eisschwund und Naturkatastrophenim Hochgebirge. Final Report NFP 31, v/d/f Hochschulverlag ETH Zurich.

Hartemink, A.E., McBratney, A.B. 2009. Geomorphometry. Concepts, Software, Applications. Developments in Soil Science, 33. Series Editors. A.E. Edited by Tomislav Hengl \& Hannes I. Reuter.

Hewitt, K., Clague, J.J., Orwin, J.F. 2008. Legacies of catastrophic rock slope failures in mountain landscapes. Earth-Science Reviews 87, 1-38. https://doi.org/10.1016/j.earscirev.2007.10.002.

Hewitt, K. 2009. Rock avalanches that travel onto glaciers and related developments Karakoram Himalaya Asia.Geomorphology 103,66-79.https://doi.org/10.1016/j.geomorph.2007.10.017.

Huang, F.M., Huang, J.S., Jiang, S.H., Zhou, C.B. 2017. Landslide displacement prediction based on multivariate chaotic model and extreme learning machine. Engineering Geology 218 , 173-186. https://doi.org/10.1016/j.enggeo.2017.01.016.

Iturrizaga, L. 2008. Paraglacial landform assemblages in the Hindukush and Karakoram Mountains. Geomorphology 95 (1-2), 27-47. https://doi.org/10.1016/j.geomorph.2006.07.030.

Jarman, D. 2006. Large rock slope failures in the Highlands of Scotland: Characterization, causes and spatial distribution. Engineering Geology 83, 161-182. https://doi.org/10.1016/j. enggeo.2005.06.030.

Johnson, B.G., Thackray, G.D., Van Kirk, R. 2007. The effect of topography, latitude, and lithology on rock glacier distribution in the Lemhi Range, central Idaho, USA. Geomorphology 91 (12), 38-50. https://doi.org/10.1016/j.geomorph.2007.01.023.

Kääb, A. 2002. Monitoring high-mountain terrain deformation from repeated air- and spaceborne optical data: examples using digital aerial imagery and ASTER data. ISPRS Journal of Photogrammetry \& Remote Sensing 57, 39-52. https://doi.org/10.1016/S09242716(02)00114-4.

Kawabata, D., Bandibas, J. 2009. Landslide susceptibility mapping using geological data, a DEM from ASTER images and an Artificial Neural Network (ANN). Geomorphology 113 (1-2), 97-109. https://doi.org/10.1016/j.geomorph.2009.06.006.

Keefer, D.K. 1984. Landslides caused by earthquakes. Geological Society of America Bulletin 95 (4), 406-421. https://doi.org/10.1130/0016-7606(1984)95<406:LCBE>2.0.CO;2.

Kellerer-Pirklbauer, A., Proske, H., Strasser, V. 2010. Paraglacial slope adjustment since the end of the Last Glacial Maximum and its long-lasting effects on secondary mass wasting processes: Hauser Kaibling. Austria Geomorphology 120, 65-76. https://doi.org/10.1016/j. geomorph.2009.09.016.

Kovanen, D., Slaymaker, O. 2015. The paraglacial geomorphology of the Fraser Lowland, southwest British Columbia and northwest Washington. Geomorphology 232, 78-93. https:// doi.org/10.1016/j.geomorph.2014.12.021.

Kraemer, P.E., Riccardi, A.C. 1997. Estratigrafía de la región comprendida entre los lagos Argentino y Viedma (49 $40^{\circ}-50^{\circ} 10^{\prime}$ lat. S), Provincia de Santa Cruz. Revista de la Asociación Geológica Argentina 52 (3), 333-360.

Leir, M., Michell, A., Ramsay, S. 2004. Regional landslide hazard susceptibility mapping for pipelines in British Columbia. Geo-engineering for the society and its environment. 57 $7^{\text {th }}$ Canadian Geotechnical Conference and the $5^{\text {th }}$ Joint CGS-IAH conference. Old Quebec, Canada, pp. 1-9.

Lo Vecchio, A., Lenzano, M.G., Richiano, S., Lenzano, L.E. 2016. Identificación y caracterización litológica mediante el uso del sensor ETM+ (Landsat 7). Caso de estudio: entorno del glaciar Upsala, Argentina. Revista de teledetección: Revista de la Asociación Española de Teledetección 46, 57-72. https://doi.org/10.4995/raet.2016.4482. 
Malagnino, E.C., Strelin, J.A. 1992. Variations of Upsala Glacier in southern Patagonia since the late Holocene to the present. In: R. Naruse, M. Aniya (Eds.), Glaciological Researches in Patagonia, 1990. Japanese Society of Snow and Ice, pp. 61-85.

Matsuoka, M., Abe, M. 2002. Rock slope failures associated with deglaciation: some examples from glaciated valleys in the Swiss Alps. Annual Report, International Geoscience 28, 11-16.

McColl, S.T. 2012. Paraglacial rock-slope stability. Geomorphology 153-154, 1-16. https://doi. org/10.1016/j.geomorph.2012.02.015.

McColl, S.T., Fuller, I.C., Anderson, B., Tate, R. 2017. Hillslope failure and paraglacial reworking of sediments in response to glacier retreat, Fox Valley, New Zealand. Geophysical Research Abstracts 19, EGU2017, 170 pp. https://meetingorganizer.copernicus.org/EGU2017/ EGU2017-170.pdf.

Mercier, D., Étienne, S., Sellier, D., André, M.F. 2009. Paraglacial gullying of sediment-mantled slopes: a case study of Colletthøgda, Kongsfjorden area, West Spitsbergen (Svalbard). Earth Surface Processes and Landforms: The Journal of the British Geomorphological Research Group 34 (13), 1772-1789. https://doi.org/10.1002/esp.1862.

Moragues, S., Lenzano, M.G., Lo Vecchio, A., Falaschi, D., Lenzano, L. 2018. Surface velocities of Upsala glacier, Southern Patagonian Andes estimated by mean of cross correlation satellite imagery: 2013-2014 period. Andean Geology 45 (1), 87-103. https://doi.org/10.5027/ andgeoV45n1-3034.

Moragues, S., Lenzano, M.G., Moreiras, S., Lo Vecchio, A., Lannutti, E., Lenzano, E. 2019. Slope instability analysis in South Patagonia applying multivariate and bivariate techniques on Landsat images during 2001-2015 period. Catena 174, 339-352. https://doi.org/10.1016/j. catena.2018.11.024.

Moreiras, S.M. 2005. Landslide susceptibility zonation in the Rio Mendoza Valley, Argentina. Geomorphology 66, 345-357. https://doi.org/10.1016/j.geomorph.2004.09.019.

Naruse, R., Casassa, G. 1985. Reconnaissance survey of some glaciers in the Southern Icefield. In: C. Nakajima (Ed.), Glaciological Studies in Patagonia Northern Icefield, 1983-1984. Data Center for Glacier Research, Japanese Society of Snow and Ice, pp. 121-133.

Naruse, R., Skvarca, P. 2000. Dynamic Features of Thinning and Retreating Glaciar Upsala, a Lacustrine Calving Glacier in Southern Patagonia. Arctic, Antarctic, and Alpine Research 32 (4), 485-491. https://doi.org/10.1080/15230430.2000.12003393.

Owen, G., Hiemstra, J.F., Matthews, J.A., McEwen, L.J. 2010. Landslide-glacier interaction in a neoparaglacial setting at Tverrbytnede, Jotunheimen, Southern Norway. Geografiska Annaler: Series A, Physical Geography 82, 421-436. https://doi.org/10.1111/j.14680459.2010.00405.x.

Paolini, L., Sobrino, J.A., Jiménez-Muñoz, J.C. 2002. Detección de deslizamientos de ladera mediante imágenes Landsat TM: El impacto de estos disturbios sobre los bosques subtropicales del noroeste de Argentina. Revista de Teledetección 18, 21-27.

Petley, D., Crick, W.O., Hart, A.B. 2002. The use of satellite imagery in landslide studies in high mountain areas. Proceedings of the Asian conference on remote sensing, Kathmandu, Nepal.

Reid, M.L., Evans, S.G. 2016. A new approach to evaluating landslide hazard in the mountain glacial environment - mass and hypsometry. Geophysical Research Abstracts 18, EGU2016, $1194 \mathrm{pp}$.

Richter, A., Marderwald, E., Hormaechea, J.L., Mendoza, L., Perdomo, R., Connon, G., Scheinert, M., Horwath, M., Dietrich, R. 2016. Lake-level variations and tides in Lago Argentino, Patagonia: insights from pressure tide gauge records. Journal of Limnology 75 (1), 62-77. https://doi.org/10.4081/jlimnol.2015.1189.

Ryder, J.M. 1971a. The stratigraphy and morphology of paraglacial alluvial fans in south central British Columbia. Canadian Journal of Earth Sciences 8, 279-298. https://doi.org/10.1139/e71-027. 
Ryder, J.M. 1971b. Some aspects of the morphometry of paraglacial alluvial fans in south central BC. Canadian Journal of Earth Sciences 8, 1252-1264. https://doi.org/10.1139/e71-114.

Sakakibara, D., Sugiyama, S., Sawagaki, T., Marinsek, S., Skvarka, P. 2013. Rapid retreat, acceleration and thinning of Glaciar Upsala, Southern Patagonia Icefield, initiated in 2008. Annals of Glaciology 54 (63), 131-138. https://doi.org/10.3189/2013AoG63A236.

Sakakibara, D., Sugiyama, S. 2014. Ice-front variations and speed changes of calving glaciers in the Southern Patagonia Icefield from 1984 to 2011. Journal of Geophysical Research: Earth Surface 119 (11), 2541-2554. https://doi.org/10.1002/2014JF003148.

Santos-González, J., González-Gutiérrez, R.B., Santos, J.A., Gómez-Villar, A., Peña-Pérez, S.A., Redondo-Vega, J.M. 2018. Topographic, lithologic and glaciation style influences on paraglacial processes in the upper Sil and Luna catchments, Cantabrian Mountains, NW Spain. Geomorphology 319, 133-146. https://doi.org/10.1016/j.geomorph.2018.07.019.

Schaefer, M., Machguth, H., Falvey, M., Casassa, G., Rignot, E. 2015. Quantifying mass balance processes on the Southern Patagonia Icefield. The Cryosphere 9, 25-35. https://doi. org/10.5194/tc-9-25-2015.

Serrano, E., Oliva, M., González-García, M., López-Moreno, J. I., González-Trueba, J., MartínMoreno, R., Gómez-Lende, M., Martín-Díaz, J., Nofre, J., Palma, P. 2018. Post-little ice age paraglacial processes and landforms in the high Iberian mountains: A review. Land Degradation \& Development 29, 4186-4208. https://doi.org/10.1002/ldr.3171.

Shulmeister, J., Davies, T.R., Evans, D.J.A., Hyatt, O.M., Tovar, D.S. 2009. Catastrophic landslides, glacier behaviour and moraine formation a view from an active plate margin. Quaternary Science Reviews 28, 1085-1096. https://doi.org/10.1016/j.quascirev.2008.11.015.

Skvarca, P., Marinsek, S., Aniya, M. 2010. Documenting 23 years of areal loss of Hielo Patagónico Sur, recent climate data and potential impact on Río Santa Cruz water discharge. In: Abstracts. International Glaciological Conference. Ice and climate change: a view from the South. Centro de Estudios Científicos, Valdivia, Chile, 82.

Shibasaki, T., Matsuura, S., Okamoto, T. 2016. Experimental evidence for shallow, slow-moving landslides activated by a decrease in ground temperature. Geophysical Research Letters 43 (13), 6975-6984. https://doi.org/10.1002/2016GL069604.

Sidle, R.C., Ochiai, H. 2006. Landslides: processes, prediction, and land use. Water Resour. Monogr. Ser. 18. AGU, Washington DC.

Singhroy, V. 2002. Landslide hazards: CEOS, The use of earth observing satellites for hazard support: Assessments and scenarios. Final report of the CEOS Disaster Management Support Group, NOAA, 98.

Slaymaker, O. 2009. Proglacial, periglacial or paraglacial? Geological Society, London, Special Publications 320 (1), 71-84. https://doi.org/10.1144/SP320.6.

Steffen, H. 1910. Viajes de Exploración y Estudio en la Patagonia Occidental 1892-1902. Tomo II. Anales Universidad de Chile, Santiago.

Strelin, J., Kaplan, M., Vandergoes, M., Denton, G., Schaefer, J. 2014. Holocene glacier history of the Lago Argentino basin, Southern Patagonian Icefield. Quaternary Science Reviews 101, 124-145. https://doi.org/10.1016/j.quascirev.2014.06.026.

Sugiyama, S., Minowa, M., Sakakibara, D., Skvarca, P., Sawagaki, T., Ohashi, Y., Naito, N., Chikita, K. 2016. Thermal structure of proglacial lakes in Patagonia. Journal of Geophysical Research: Earth Surface 121, 2270-2286. https://doi.org/10.1002/2016JF004084.

Tofelde, S., Dusing, W., Schildgen, T.F., Wittmann, H., Alonso, R.N., Strecker, M.R. 2017. Changes in denudation rates and erosion processes in the transition from a low-relief, arid orogen interior to a high-relief, humid mountain-front setting, Toro Basin, southern Central Andes. American Geophysical Union, Fall Meeting 2017, abstract. http://adsabs.harvard. edu/abs/2017AGUFMEP33B1946T. 
Tooth, S., Viles, H. 2014. 10 reasons why is important Geomorphology. 1-17. http://www. geomorph.org/2016/06/10-reasons-why-geomorphology-is-important-by-stephen-toothand-heather-viles/.

Varnes, D.J. 1978. Slope movement types and processes. In: R.L. Schuster, R.J. Krizek (Eds.), Landslides, analysis and control, special report 176: Transportation research board, National Academy of Sciences, Washington, DC, pp. 11-33. http://onlinepubs.trb.org/Onlinepubs/sr/ sr176/176-002.pdf.

Villalba, R., Masiokas, M., Ruiz, L., Pitte, P., Rivera, J., Viale, M. 2017. Impactos del Cambio Climático en el Régimen Hidrológico del Río Santa Cruz. Instituto Argentino de Nivología, Glaciología y Ciencias Ambientales (IANIGLA), CONICET. Informe Técnico.

Williams, P.J., Smith, M.W. 1989. The frozen earth: fundamentals of geocryology. Cambridge University Press, Cambridge, UK. https://doi.org/10.1017/CBO9780511564437.

Willis, M., Melkonian, A.K., Pritchard, M.E., Rivera, A. 2012. Ice loss from the Southern Patagonian Ice Field, South America, between 2000 and 2012. Geophysical Research Letters 39, 1-6. https://doi.org/10.1029/2012GL053136.

Winocur, D., Goyanes, G., Viera, G. 2015. Deslizamiento de ladera y tsunami asociado en el Lago Argentino, Canal Upsala, provincia de Santa Cruz, Patagonia Argentina. Congreso Geológico Chileno, La Serena, Chile, pp. 136-139. http://biblioteca.sernageomin.cl/opac/ DataFiles/14905_v3_pp_79_82.pdf.

Zêzere, J., Ferreira, A., Rodrigues, M. 1999. The role of conditioning and triggering factors in the occurrence of landslides: a case study in the area north of Lisbon (Portugal). Geomorphology 30, 133-146. https://doi.org/10.1016/S0169-555X(99)00050-1.

Zinck, J.A. 2012. Geopedología. Elementos de geomorfología para estudios de suelos y de riesgos naturales. ITC. Faculty of Geo-Information Science and Earth Observation Enschede, the Netherlands, pp. 123-131. https://webapps.itc.utwente.nl/librarywww/papers_2012/general/ zinck_geopedologia_2012.pdf.

Zischinsky, U. 1969. Über Sackungen. Rock Mechanics 1, 30-52. https://doi.org/10.1007/ BF01247356. 